\title{
Treating the Many Using a Few: A Novel Approach for the Application of External Fixators in Mass Casualties
}

\author{
Alexandros Vris ${ }^{1}$, Ossama Al-Obaedi ${ }^{2}$, Kalpesh R Vaghela ${ }^{3}$, Nima Heidari ${ }^{4}$
}

\begin{abstract}
Aim: The aim of this is to allow the use of unsterile kit (clamps and rods) in situations where the demand for external limb fixators exceeds the available sterile equipment.

Background: In view of the recent rise in violence and terrorist activity, we have to be prepared for situations causing major incidences. These can place a large strain on our operating theaters and the available surgical kit due to the potential number of casualties.

Materials and methods: We propose a sterile dressing technique during the application of an external limb fixator that provides an adequate seal around the pin sites and allows the use of simply decontaminated external fixator parts.

Conclusion: This technique prevents the intraoperative contamination of the clamps and connecting rods, which allow for a sterile barrier to minimize pin site infections.

Keywords: Dressings, External fixators, Major incidents, Mass casualties, Trauma centers.

Strategies in Trauma and Limb Reconstruction (2019): 10.5005/jp-journals-10080-1428
\end{abstract}

\section{INTRODUCTION}

Given the recent terrorist activity in the United Kingdom and continental Europe, hospitals across the United Kingdom have been involved in simulation exercises to assess the preparedness for similar attacks. The main focus during such situations is damage control. The number of patients requiring external fixators in these scenarios is unpredictable and may well exceed the amount available in local hospitals. Our technique describes a safe way to maintain an adequate seal around the pin sites and allows the use of unsterile decontaminated clamps and rods. This immediately increases the amount of available kit in such major incident scenarios.

\section{Surgical Technique}

The application of the external fixator is performed under general anesthesia and with the patient in the supine position. An image intensifier is required. The external fixator pins are inserted based on the fracture configuration and with consideration of the zone of injury. The pin sites are dressed in the desired fashion (Fig. 1). In the context of an open fracture, the wounds can be managed with standard or negative pressure dressings. Sterile wool and elastic bandages are applied around the limb leaving only the pin shafts exposed (Fig. 2), and the surgical field is re-draped. Finally, with clean gloves, the connecting bars and rods are assembled to complete the external fixator (Fig. 3) and the position is adjusted under imaging before final tightening.

\section{Discussion}

The surgical technique, pin design, frequency of pin site dressings, and dressing types have all been previously investigated in the literature. However, there is not one factor that has been shown to have a significant impact on the incidence of pin site infections. ${ }^{1,2}$ Several authors have described dressing techniques that include wrapping the whole limb in a sterile bandage or using rubber bungs

\begin{abstract}
${ }^{1-4}$ Department of Trauma and Orthopaedic Surgery, The Royal London Hospital, London, UK

Corresponding Author: Alexandros Vris, Department of Trauma and Orthopaedic Surgery, The Royal London Hospital, London, UK, Phone: +44 7473270965, e-mail: avris@nhs.net

How to cite this article: Vris A, Al-Obaedi O, Vaghela KR, et al. Treating the Many Using a Few: A Novel Approach for the Application of External Fixators in Mass Casualties. Strategies Trauma Limb Reconstr 2019;14(2):92-93.
\end{abstract}

\section{Source of support: Nil}

Conflict of interest: None

from a syringe to provide a secure seal around the pin sites. ${ }^{3,4}$ Our simple technique allows the use of unsterile decontaminated bars and rods in situations where the demand for these external fixators

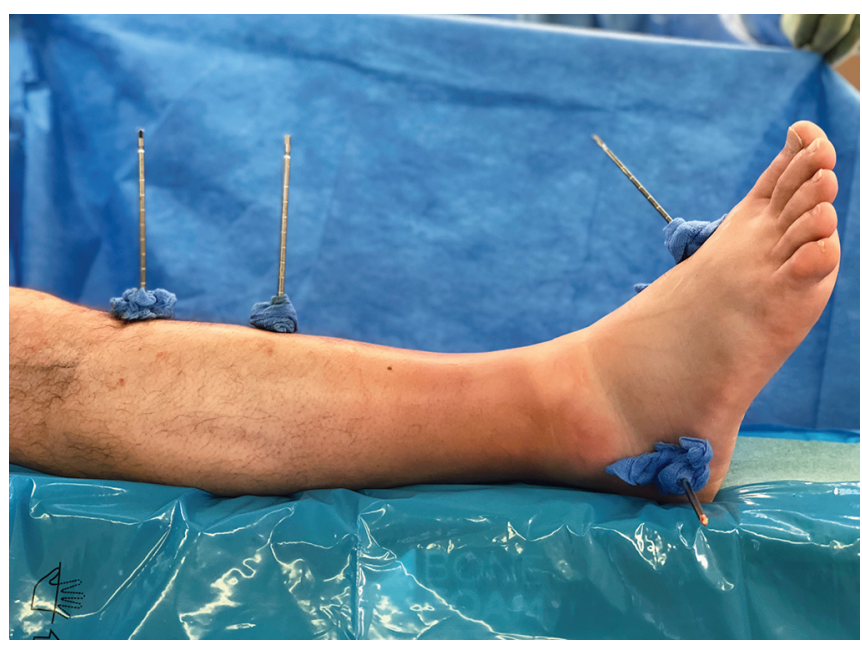

Fig. 1: External fixator pins in tibia shaft, calcaneus and first metatarsal are applied under sterile conditions. The pin sites are covered with sterile dressings 


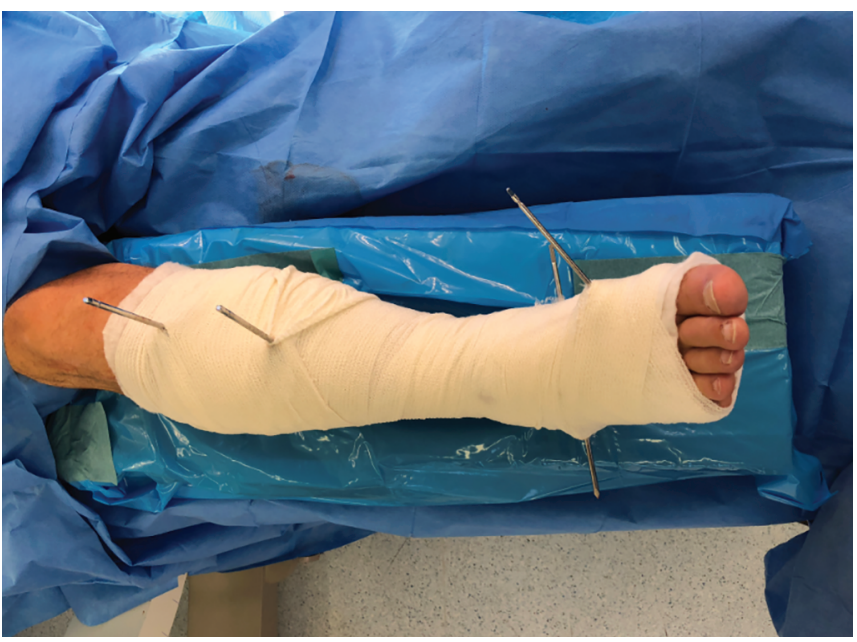

Fig. 2: The leg is wrapped with a sterile bandage including the pin sites

surpasses the availability of sterile kit. Additionally, it prevents contamination of the connecting clamps and rods with blood and provides a sterile barrier to help minimize pin site infection. Large stock of unsterile, decontaminated external fixator parts can be made available in every hospital by collecting the reusable parts when removing external fixators in the operating theater or outpatient clinics.

With the rise in terrorist activity in the last few years, we have to be prepared for major incident situations. This refers to a large number of casualties with limb trauma, arriving to accident and emergency. The priority in these situations is to provide resuscitation and damage control surgery. The difficulty will arise if all the available kits have been used when more casualties require temporary skeletal stabilization. At present, in our major trauma center, we have six external fixator sets in total (three Hoffmann and three Synthes). This can be a very small number for these scenarios and highlights the need to consider these alternative means to maximize the use of available kit. The indicative cost for acquiring one new set is $£ 40,000$ for Stryker and $£ 25,000$ for Synthes. The quality and versatility of both these sets is exceptional and comes at a high cost but is not necessary in damage control surgery during mass casualty situations. Other solutions in the market include single use, limb specific sterile sets that still come at a high cost.

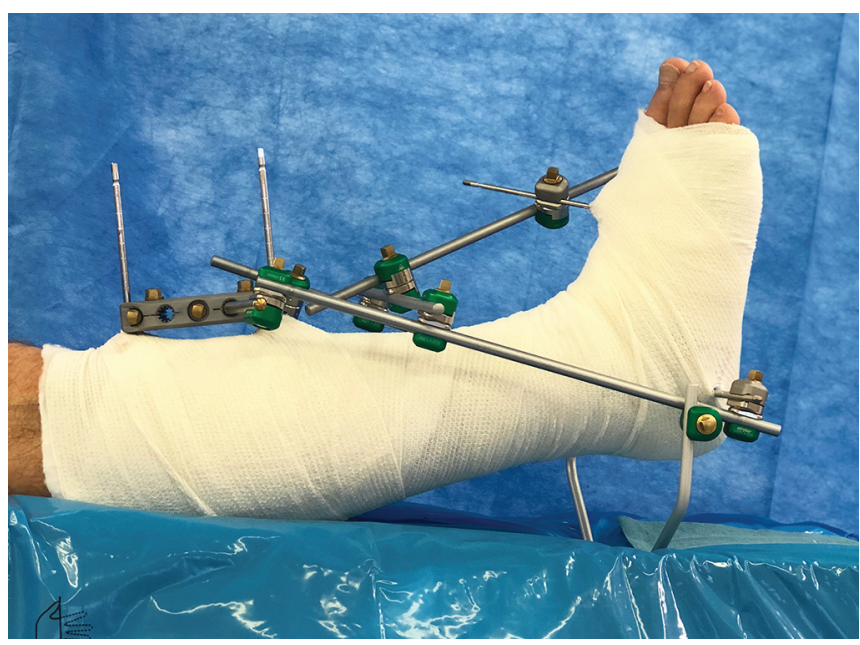

Fig. 3: The rest of the external fixator components (decontaminated rods and clamps) can be applied in a non-sterile fashion around the "sealed" pin sites. X-ray guidance can be used for optimal reduction at this stage

\section{Conclusion}

Our proposed dressing technique allows the use of unsterile decontaminated rods and clamps which is of great value in situations where the demand of external fixators exceeds the number of available sterile equipment. Additionally, it prevents contamination of the connecting clamps and rods with blood and provides a sterile barrier that could minimize pin site infection.

\section{References}

1. Kazmers NH, Fragomen AT, Rozbruch SR. Prevention of pin site infection in external fixation: a review of the literature. Strategies Trauma Limb Reconstr 2016;11(2):75-85. DOI: 10.1007/s11751-016-0256-4.

2. Annette $W$, Toksvig-Larsen $S$. Undisturbed theatre dressing during the first postoperative week. A benefit in the treatment by external fixation: a cohort study. Strategies Trauma Limb Reconstr 2009;4(1): 7-12. DOI: 10.1007/s11751-009-0053-4.

3. Talbot NJ, Annapureddy SR, Becker GW, et al. A simple method of dressing external fixator pin sites. Ann R Coll Surg Engl 2005;87(3):206-207.

4. Ferreira N, Marais LC. Prevention and management of external fixator pin track sepsis. Strategies Trauma Limb Reconstr 2012;7(2):67-72. DOI: 10.1007/s11751-012-0139-2. 